\title{
Class I Polyhydroxyalkanoate Synthase from the Purple Photosynthetic Bacterium Rhodovulum sulfidophilum Predominantly Exists as a Functional Dimer in the Absence of a Substrate
}

\author{
Mieko Higuchi-Takeuchi, ${ }^{\dagger}$ Yoko Motoda, ${ }^{\dagger}$ Takanori Kigawa, ${ }^{\dagger}$ and Keiji Numata ${ }^{*}{ }^{\dagger} \odot$ \\ ${ }^{\dagger}$ Enzyme Research Team, Biomass Engineering Research Division, RIKEN Center for Sustainable Resource Science, 2-1 Hirosawa, \\ Wako-shi, Saitama 351-0198, Japan. \\ ${ }^{\ddagger}$ Laboratory for Biomolecular Structure and Dynamics, RIKEN Quantitative Biology Center, 1-7-22 Suehiro-cho, Tsurumi-ku, \\ Yokohama 230-0045, Japan.
}

\section{Supporting Information}
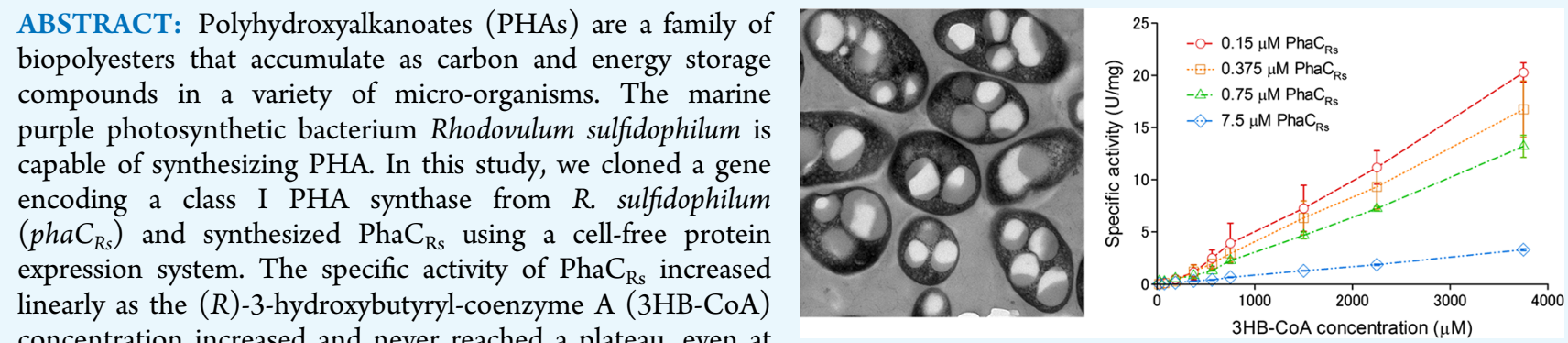
concentration increased and never reached a plateau, even at $3.75 \mathrm{mM} 3 \mathrm{HB}-\mathrm{CoA}$, suggesting that $\mathrm{PhaC}_{\mathrm{Rs}}$ was not saturated because of low substrate affinity. Size exclusion chromatography and native polyacrylamide gel electrophoresis analyses revealed that $\mathrm{PhaC}_{\mathrm{Rs}}$ exists predominantly as an active dimer even in the absence of $3 \mathrm{HB}-\mathrm{CoA}$, unlike previously characterized PhaCs. The linear relationship between the $\mathrm{PhaC}_{\mathrm{Rs}}$ activity and $3 \mathrm{HB}-\mathrm{CoA}$ concentrations could result from a low substrate affinity as well as the absence of a rate-limiting step during PHA polymerization because of the existence of predominantly active dimers.

\section{INTRODUCTION}

Polyhydroxyalkanoates (PHAs) are biopolyesters that accumulate in many organisms in the presence of excess carbon and limited nutrient sources. PHAs have attracted attention as an alternative source to petroleum-derived plastics, and their properties, such as biodegradability and biocompatibility, have been extensively studied. ${ }^{1}$ PHAs require a cost-consuming carbon source, such as sugars or plant oils. Therefore, many studies have focused on photosynthetic organisms as hosts for PHA production because carbon dioxide can be directly used as a carbon source. ${ }^{2,3}$ Most studies regarding PHA production via photosynthesis have been carried out using oxygenic phototrophs, such as higher plants and cyanobacteria. ${ }^{4-6}$ However, high levels of photosynthesis-mediated PHA production have not yet been achieved. Although anoxygenic photosynthetic bacteria produce higher amounts of PHA compared with plants and cyanobacteria, ${ }^{7,8}$ these bacteria, particularly marine photosynthetic bacteria, have not been extensively studied.

PHA synthase (PhaC) is a key enzyme involved in PHA biosynthesis, and it catalyzes the polymerization of (R)-3hydroxyacyl-coenzyme A ( CoA) to PHA. PhaC has been categorized into four classes based on its subunit composition, sequence similarity, and substrate specificity. ${ }^{9}$ Class I and II synthases consist of a single subunit, and class II PhaCs are composed of two different phaC genes (phaC1 and phaC2) separated by phaZ, which encodes PHA depolymerase. Class III synthases are composed of two subunits, $\mathrm{PhaC}$ and $\mathrm{PhaE}$, whereas class IV synthases are composed of the subunits $\mathrm{PhaC}$ and PhaR. Classes I, III, and IV preferentially use short-chainlength (three to five carbon atoms) CoA thioesters, whereas class II synthases catalyze the polymerization of medium-chainlength (more than six carbon atoms) CoA thioesters. Ralstonia eutropha ( $R$ eutropha) H16 is one of the best-known PHAproducing bacteria and has a class I PhaC. PhaC from the purple sulfur photosynthetic bacterium Allochromatium vinosum (A. vinosum) is categorized as a class III synthase whose biochemical properties have been extensively studied. ${ }^{10-12}$ In our previous studies, we reported the in vitro specific activity of class I PhaC from Aeromonas caviae (A. caviae) ${ }^{13}$ and class III $\mathrm{PhaC}$ and PhaE from Synechocystis sp. PCC6803 (Synechocystis), ${ }^{14}$ using a cell-free protein expression system. These studies demonstrated that the dimeric form of PhaC containing $(R)$-3hydroxybutyryl (3HB)-CoA is an active form that catalyzes the polymerization. Recently, crystal structures of the C-terminal domain (residues 201-589) of PhaC from R. eutropha at $1.8 \AA$

Received: May 25, 2017

Accepted: July 21, 2017

Published: August 29, 2017 
(A)

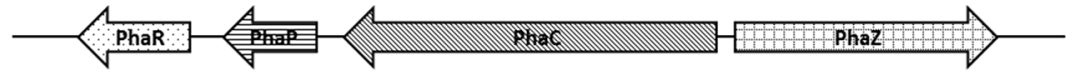

(B)

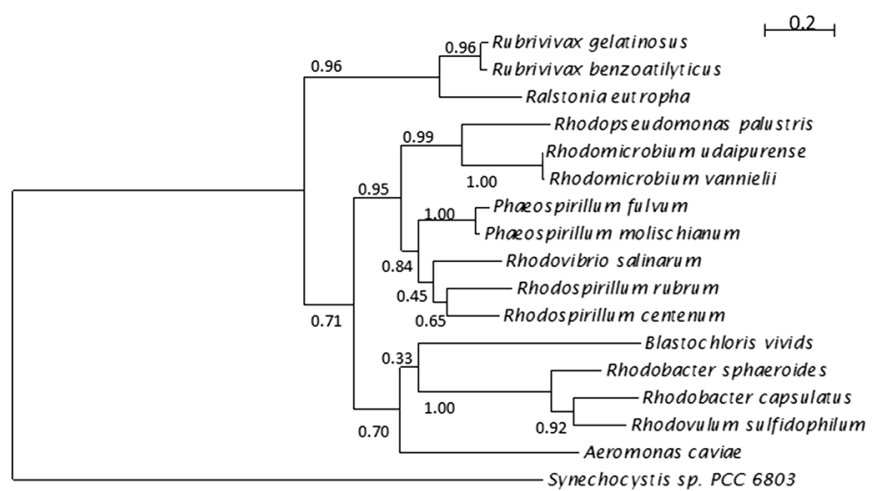

(C)

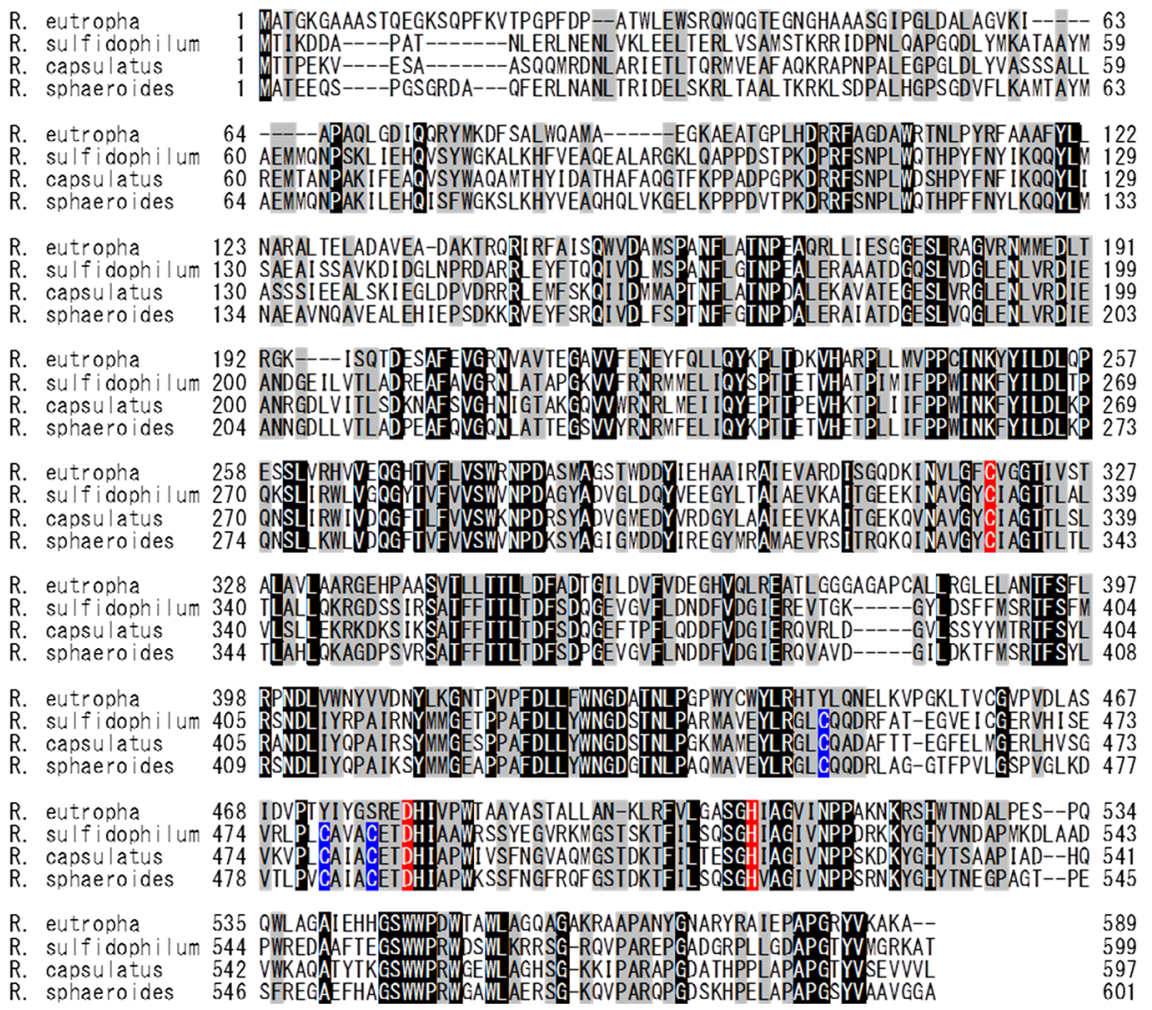

Figure 1. PhaC from R. sulfidophilum. (A) Genetic organization of PHA biosynthesis genes in the R. sulfidophilum genome. (B) Phylogenetic tree of $\mathrm{PhaC}$ from purple nonsulfur bacteria. The accession numbers are as follows: WP_043812714 (Rubrivivax gelatinosus), WP 009856865 (Rubrivivax benzoatilyticus), WP_011615085 (Ralstonia eutropha), WP_013502713 (Rhodopseudomonas palustris), KAI96413 (Rhodomicrobium udaipurense), ADP70651 (Rhodomicrobium vannielii), EPY03196 (Phäeospirillum fulvum), CCG41701 (Phaeospirillum molischianum), WP 027288919 (Rhodovibrio salinarum), and CAB65395 (R. rubrum). Synechocystis sp. PCC6803 was used as an outgroup. (C) Amino acid sequence alignment of PhaC from $R$. sulfidophilum, $R$. capsulatus, $R$. sphaeroides, and $R$. eutropha. The amino acid sequences were aligned using the MUSCLE algorithm. The amino acids of the catalytic triad are shown in red boxes. The conserved Cys residues are shown in blue boxes.

resolution were reported. ${ }^{15,16}$ These analyses also revealed that the $\mathrm{PhaC}$ dimer is active during PHA polymerization.

Our previous study demonstrated that some species of marine purple photosynthetic bacteria could accumulate PHA. ${ }^{8}$ All purple nonsulfur bacteria accumulated PHA in the absence of nutrient deficiency, and some of them produced highmolecular-weight PHA, unlike the well-known PHA-producing bacteria. Although these PHA properties might be derived from the enzymatic characteristics of $\mathrm{PhaC}$, those from marine purple nonsulfur bacteria have not yet been studied. Rhodovulum sulfidophilum, a marine purple nonsulfur photo- synthetic bacterium, was characterized in our study. $R$. sulfidophilum can synthesize PHA, ${ }^{17}$ and its genome has been completely sequenced. ${ }^{18}$

In this work, we discovered a phaC gene in the $R$. sulfidophilum genome, and it was categorized as a class I synthase, unlike those of A. vinosum and Synechocystis. We previously reported that PHA production conditions and PHA compositions of purple nonsulfur bacteria differed from those of purple sulfur bacteria and cyanobacteria. ${ }^{8}$ Here, we characterized $\mathrm{PhaC}$ from $R$. sulfidophilum $\left(\mathrm{PhaC}_{\mathrm{Rs}}\right)$ in vitro using a cell-free protein expression system and demonstrated 
that $\mathrm{PhaC}_{\mathrm{Rs}}$ exists preferentially in a constitutively active dimeric form even in the absence of a substrate, unlike the wellknown PHA-producing bacteria. Elucidating these intriguing properties of PhaC from $R$. sulfidophilum will contribute to industrial PHA production and to a better understanding of the PHA polymerization mechanism.

\section{RESULTS}

PhaC from $R$. sulfidophilum and Cell-Free Synthesis. We found two homologous genes encoding PhaC proteins (WP_042463846 and WP_042457276), which are composed of $59 \overline{9}$ and 585 amino acids, respectively, in the R. sulfidophilum genome. The amino acid residues of the two proteins share 35 and $33 \%$ identity to that of PhaC from $R$. eutropha. PHA biosynthesis-related genes are clustered in bacterial genomes. ${ }^{9}$ In the R. sulfidophilum genome, the phaP gene encoding Phasin and the phaR gene encoding the PHA repressor protein are located downstream of the phaC gene encoding WP_042463846 (Figure 1A). The phaZ gene encoding the $\mathrm{PH} \overline{\mathrm{A}}$ depolymerase is located next to the phaC gene, and these genes are transcribed in opposite directions. The other phaC gene encoding WP_042457276 did not colocalize with any PHA biosynthesis-related genes. We analyzed the promoter regions using BPROM, a bacterial promoter prediction program. ${ }^{19}$ Recognition sites were found in the upstream region of the phaC gene encoding WP_042463846 but were not found in the gene encoding WP_042 457276 . Quantitative reverse transcription-polymerase chain reaction (RT-PCR) analysis was carried out to determine the expression levels of two phaC genes (WP_042463846 and WP_042457276). The expression level of the phaC gene encoding WP_042463846 was 1844-fold higher than that of the other phaC gene encoding WP_042457276. This observation strongly supports that the pha $\bar{C}$ gene encoding WP_042463846 is an actively expressed gene. Therefore, the phaC gene encoding WP_ 042463846 was used for further analysis and is hereafter referred to as $\mathrm{PhaC}_{\mathrm{Rs}}$.

The phylogenetic tree was generated using $\mathrm{PhaC}$ amino acid sequences from 14 purple nonsulfur photosynthetic bacteria as well as from A. caviae, $R$ eutropha, and Synechocystis (Figure 1B). As with $R$. sulfidophilum, almost all purple nonsulfur bacteria have multiple homologous phaC genes in their genome. PhaCs that exhibit a higher amino acid sequence identity compared with that of $R$. eutropha were selected for alignment analysis. $\mathrm{PhaC}_{\mathrm{Rs}}$ is close to those of Rhodobacter sphaeroides ( $R$. sphaeroides) and Rhodobacter capsulatus ( $R$. capsulatus). The amino acid alignment of PhaC from $R$. sulfidophilum, $R$. sphaeroides, $R$. capsulatus, and $R$. eutropha is shown in Figure 1C. For $R$ eutropha, C319, D480, and H508 form a Cys-His-Asp catalytic dyad for the covalent catalysis. C319 is proposed to serve as a catalytic nucleophile, D480 acts as the general base catalyst, and H508 deprotonates C319 for nucleophilic attack from the HB-CoA thioester. C331, D486, and $\mathrm{H} 515$ in $R$. sulfidophilum were conserved in all PhaCs, suggesting that these three amino acids correspond to C319, D480, and H508 in R. eutropha; these amino acids are catalytic residues for PHA polymerization.

The genomic region of $\mathrm{PhaC}_{\mathrm{Rs}}$ was cloned from the genomic DNA extracted from $R$. sulfidophilum and was used for the cellfree synthesis. The $\mathrm{PhaC}_{\mathrm{Rs}}$ expression was evaluated by sodium dodecyl sulfate polyacrylamide gel electrophoresis (SDSPAGE) (Figure S2), and the major band was approximately $66 \mathrm{kDa}$, which corresponds to $\mathrm{PhaC}_{\mathrm{Rs}}$. To purify PhaC, an N11 tag with a tobacco etch virus (TEV) protease recognition sequence was inserted. After TEV treatment, $\mathrm{PhaC}_{\mathrm{Rs}}$ was purified with a nickel-nitrilotriacetic acid (Ni-NTA) column. A $36 \mathrm{~mL}$ reaction mixture yielded $2.8 \mathrm{mg}$ of purified $\mathrm{PhaC}_{\mathrm{Rs}}$.

$\mathrm{PhaC}_{\mathrm{Rs}}$ Polymerization Activity. The purified $\mathrm{PhaC}_{\mathrm{Rs}}$ was mixed with $100 \mathrm{mM}$ sodium phosphate $(\mathrm{pH} 7.5)$ containing $0.12 \mathrm{mM}$ Triton X-100 and characterized using a polymerization activity assay with $3 \mathrm{HB}-\mathrm{CoA}$. The polymerization activity of various concentrations of $\mathrm{PhaC}_{\mathrm{Rs}}(0.75,7.5,10$, and $15 \mu \mathrm{M})$ was evaluated using $750 \mu \mathrm{M}$ 3HB-CoA. The polymerization activity was increased at $0.75 \mu \mathrm{M} \mathrm{PhaC} \mathrm{Ps}_{\mathrm{Rs}}$ and showed similar levels at concentrations greater than $7.5 \mu \mathrm{M}$ (Figure 2A). Consequently, the specific activity decreased as
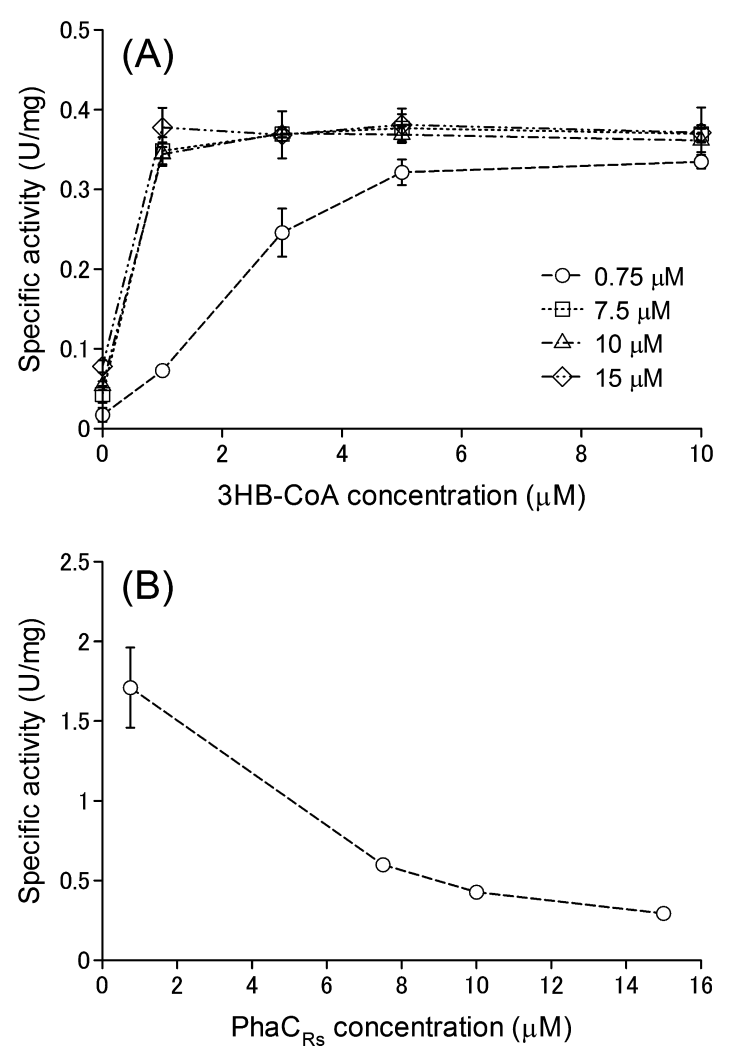

Figure 2. Time course of the release of CoA from 3HB-CoA catalyzed by $\mathrm{PhaC}_{\mathrm{Rs}}$. (A) Concentrations of $\mathrm{PhaC}_{\mathrm{Rs}}$ ranging from 0.75 to $15 \mu \mathrm{M}$ used in the presence of $750 \mu \mathrm{M} 3 \mathrm{HB}-\mathrm{CoA}$. (B) Specific activity of $\mathrm{PhaC}_{\mathrm{Rs}}$ as a function of changes in its concentration. The concentration of $3 \mathrm{HB}-\mathrm{CoA}$ was $750 \mu \mathrm{M}$. The Error bars represent the standard deviation of three independent experiments.

the $\mathrm{PhaC}_{\mathrm{Rs}}$ concentration increased (Figure 2B), unlike Synechocystis and A. caviae. ${ }^{20,21}$ In Synechocystis and A. caviae, the specific activity is saturated at approximately $1000 \mu \mathrm{M}$ $3 \mathrm{HB}-\mathrm{CoA} .^{20,21}$ The effects of various $3 \mathrm{HB}-\mathrm{CoA}$ concentrations on the polymerase activity were evaluated using different concentrations of $\mathrm{PhaC}_{\mathrm{Rs}}$ (Figure 3). The specific activity increased sequentially as the $3 \mathrm{HB}-\mathrm{CoA}$ concentration increased and was never saturated, even at $3750 \mu \mathrm{M} 3 \mathrm{HB}-\mathrm{CoA}$. These results indicate that this substrate is not sufficient to fully activate $\mathrm{PhaC}_{\mathrm{Rs}}$. PhaCs from A. caviae ${ }^{22}$ and Rhodospirillum rubrum ${ }^{23}$ have been shown to use the C6-monomer $(3 \mathrm{HHx}-$ $\mathrm{CoA}$ ) as a substrate; thus, $3 \mathrm{HHx}-\mathrm{CoA}$ was used as a $\mathrm{PhaC}_{\mathrm{Rs}}$ substrate. $\mathrm{PhaC}_{\mathrm{Rs}}$ showed negligible activity toward $3 \mathrm{HHx}-\mathrm{CoA}$ (Figure 4), indicating that $3 \mathrm{HB}-\mathrm{CoA}$ is required for the polymerase reaction of $\mathrm{PhaC}_{\mathrm{Rs}}$. 


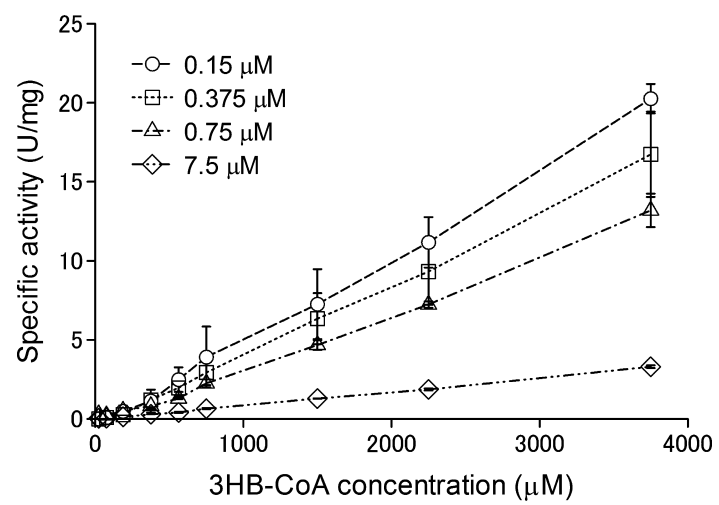

Figure 3. Effect of 3HB-CoA concentrations on the specific activity of $\mathrm{PhaC}_{\mathrm{Rs}}$. The concentrations of $\mathrm{PhaC}_{\mathrm{Rs}}$ ranged from 0.15 to $7.5 \mu \mathrm{M}$. The error bars represent the standard deviation of three independent experiments.

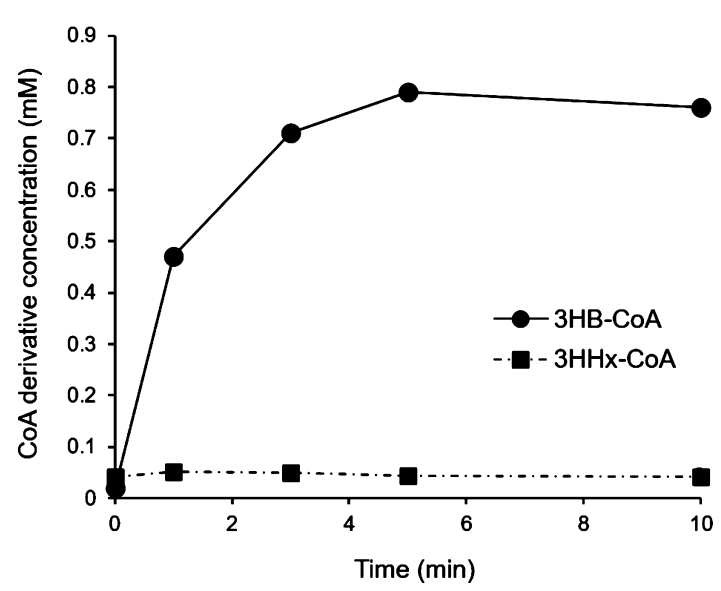

Figure 4. Time course of the release of CoA from 3HHx-CoA. The concentrations of $3 \mathrm{HB}-\mathrm{CoA}$ and $3 \mathrm{HHx}-\mathrm{CoA}$ were both $1.5 \mathrm{mM}$. The concentration of $\mathrm{PhaC}_{\mathrm{Rs}}$ was $7.5 \mu \mathrm{M}$.

Size Exclusion Chromatography and Native PAGE Analysis of $\mathrm{PhaC}_{\mathrm{Rs}}$. The dimeric formation of $\mathrm{PhaC}$ is important for its polymerization activity according to previous studies. ${ }^{24,25}$ The multimerization of $\mathrm{PhaC}_{\mathrm{Rs}}$ was evaluated at various $3 \mathrm{HB}-\mathrm{CoA}$ concentrations by size exclusion chromatography (Figure 5A). Four peaks were detected at 6.2, 6.7, 9.2, and $12.3 \mathrm{~min}$. The peak at approximately $12.3 \mathrm{~min}$ corresponded to $3 \mathrm{HB}-\mathrm{CoA}$. According to the calibration curve generated from the elution times of the molecular standards, the molecular weights corresponding to peaks with elution times of 6.2, 6.7, and 9.2 min were estimated to be 185 , 166 , and $71 \mathrm{kDa}$, respectively. Interestingly, a peak shift was not observed when 3HB-CoA was added, although a slight change in the peak height was observed. Native PAGE analysis of each fraction resulting from size exclusion chromatography was performed to verify the multimer formation of $\mathrm{PhaC}_{\mathrm{Rs}}$ (Figure 5B). Peak 1 (elution time of approximately $6 \mathrm{~min}$ ) and peak 2 (elution time of approximately $9 \mathrm{~min}$ ) fractions contained dimeric forms of $\mathrm{PhaC}$ based on their corresponding molecular weights. The peak 1 fraction also contained high-molecularweight aggregates owing to multimeric $\mathrm{PhaC}$. The molecular weight of peak 2 at 9.2 min was estimated to be $71 \mathrm{kDa}$, which likely corresponds to the $\mathrm{PhaC}_{\mathrm{Rs}}$ monomer $(67 \mathrm{kDa})$. Native PAGE analysis revealed that the peak 1 fraction contained the dimeric form of $\mathrm{PhaC}_{\mathrm{Rs}}$. This apparent difference may be explained by the compact structure of the $\mathrm{PhaC}_{\mathrm{Rs}}$ dimer. As shown in Figure 5A, the elution times were almost identical in the presence and absence of $3 \mathrm{HB}-\mathrm{CoA}$. These results indicate that $3 \mathrm{HB}-\mathrm{CoA}$ is not required for $\mathrm{PhaC}_{\mathrm{Rs}}$ dimerization.

The cysteine (Cys) residue plays an important role in PHA polymerization. Two thiol groups from the Cys residues on each $\mathrm{PhaC}$ monomer are proposed to be required for the catalytic site formation. ${ }^{26}$ In addition to $\mathrm{C} 331, \mathrm{PhaC}_{\mathrm{Rs}}$ contains four Cys residues (C452, C465, C479, and C483). Phylogenetic analysis revealed that $\mathrm{PhaC}_{\mathrm{Rs}}$ was close to those of $R$. capsulatus and R. sphaeroides (Figure 1B). Amino acid sequences of $R$. sulfidophilum, $R$. capsulatus, and $R$. sphaeroides were compared with that of $R$ eutropha (Figure 1C). C452, C479, and C483 were conserved in three purple nonsulfur bacteria, and these three Cys residues might affect $\mathrm{PhaC}_{\mathrm{Rs}}$ dimerization. To verify this possibility, tris(2-carboxyethyl)phosphine (TCEP) was used to reduce disulfide bonds, and the multimerization of $\mathrm{PhaC}_{\mathrm{Rs}}$ was analyzed in the presence of 10 $\mathrm{mM}$ TCEP by size exclusion chromatography (Figure S3). The high-molecular-weight aggregation fraction (peak 1) was increased by TCEP treatment. However, no significant peak shift was observed by treatment with TCEP, suggesting that disulfide bonds are not required for dimerization because $\mathrm{PhaC}_{\mathrm{Rs}}$ formed stable dimers even in the reduced state.
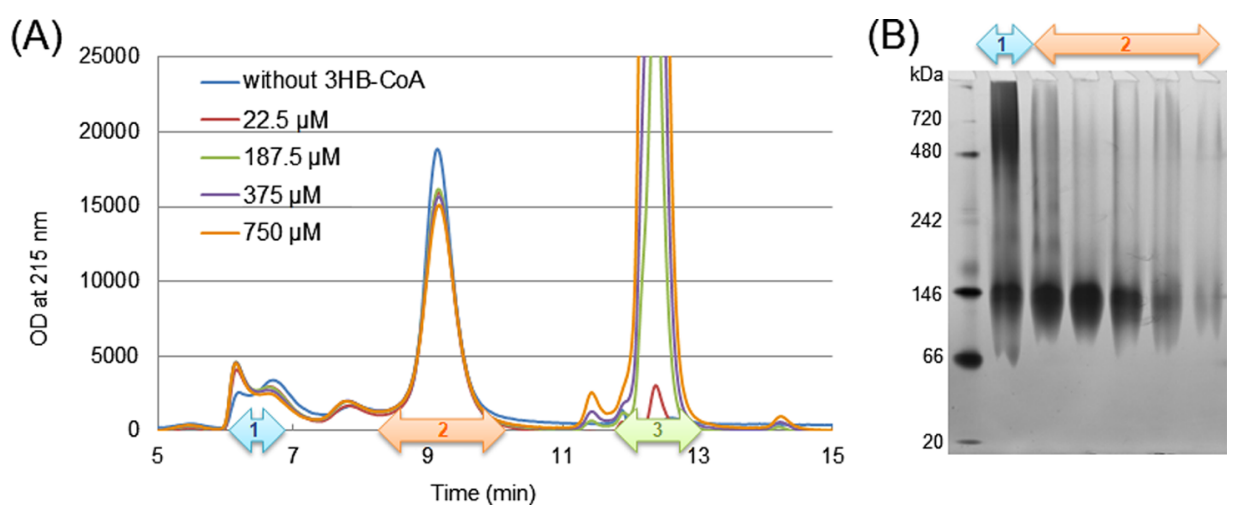

Figure 5. Analysis of $\mathrm{PhaC}_{\mathrm{Rs}}$ monomer-dimer formation. (A) Size exclusion chromatography profiles of $\mathrm{PhaC}_{\mathrm{Rs}}$. Concentrations of $3 \mathrm{HB}-\mathrm{CoA}$ ranging from 0 to $750 \mu \mathrm{M}$ were used for the analysis. The two peaks are labeled peak 1 and peak 2 . The $\mathrm{PhaC}_{\mathrm{Rs}}$ concentration was $7.5 \mu \mathrm{M}$. (B) Native PAGE analysis of samples collected from peaks 1 and 2 . The $\mathrm{PhaC}_{\mathrm{Rs}}$ and $3 \mathrm{HB}-\mathrm{CoA}$ concentrations were 75 and $225 \mu \mathrm{M}$, respectively. Peak 1 and peak 2: dimeric $\mathrm{PhaC}_{\mathrm{Rs}}$; peak 3: 3HB-CoA. 


\section{DISCUSSION}

In this study, we cloned a class I PhaC from $R$. sulfidophilum and synthesized $\mathrm{PhaC}_{\mathrm{Rs}}$ using a cell-free protein expression system. We demonstrated that the properties of $\mathrm{PhaC}_{\mathrm{Rs}}$ differ from those of other well-known PHA-producing bacteria. Monomeric and dimeric forms of $\mathrm{PhaC}$ exist as an equilibrium in vitro, and dimerization is induced in the presence of a substrate. ${ }^{13,14,24}$ Surprisingly, size exclusion chromatography and native PAGE analyses revealed that the dimeric form of $\mathrm{PhaC}_{\mathrm{Rs}}$ was dominant even in the absence of 3HB-CoA (Figure 5). Although a minor fraction of the $\mathrm{PhaC}$ dimer was previously observed in the absence of a substrate in other bacteria, ${ }^{13,24}$ to the best of our knowledge, the predominance of the PhaC dimer has not been described until now. We discovered four conserved Cys residues among three purple nonsulfur bacteria (C331, C452, C479, and C483) and demonstrated that $\mathrm{PhaC}_{\mathrm{Rs}}$ exists as a dimer in the reduced state (Figure S3). The lack of $\mathrm{PhaC}_{\mathrm{Rs}}$ monomers could be due to the fast association of the monomers with dimers and the stable formation of the dimer. Disulfide bonds are known to increase the conformational stability of many proteins. ${ }^{27}$ Conserved Cys residues in $\mathrm{PhaC}_{\mathrm{Rs}}$ might affect the stability of the dimer, which would lead to the predominance of the dimeric form. Cys residues also have important roles in sensing the changes in the cellular redox status. Many thioredoxin target proteins whose activities are controlled by the reduction of disulfide bonds have been identified in cyanobacteria and chloroplasts. ${ }^{28}$ In purple nonsulfur bacteria, the RegB/RegA two-component system, ${ }^{29}$ the AppA/PpsR transcription factor system, ${ }^{30}$ and the transcription factors CrtJ and $\mathrm{Fnr}^{31}$ are known to be associated with the redox-responding regulators via the thiol-disulfide exchange reaction. The activity of $\mathrm{PhaC}_{\mathrm{Rs}}$ might be controlled by the redox state through the thiol-disulfide exchange between conserved Cys residues. $R$. sulfidophilum has two homologous phaC genes in the genome, as previously described. Although the expression level of the second phaC gene was quite low, it is still possible that PHA polymerization is regulated through the $\mathrm{PhaC}$ heterodimers.

$\mathrm{PhaC}_{\mathrm{Rs}}$ activity never reached a plateau, even at very high concentrations of 3HB-CoA, as shown in Figure 3, suggesting that this substrate was not sufficient to fully activate $\mathrm{PhaC}_{\mathrm{Rs}}$. As a result, the specific activity decreased as the $\mathrm{PhaC}_{\mathrm{Rs}}$ concentration increased (Figure $2 \mathrm{~B}$ ). The predominant dimeric form could affect these $\mathrm{PhaC}_{\mathrm{Rs}}$ properties. The PHA polymerization process occurs in three steps: initiation, elongation, and termination. Regarding PhaC from $R$. eutropha, the chain initiation rate is slower than the chain elongation rate. ${ }^{32}$ The dimerization and binding of 3HB-CoA are assumed to be the rate-limiting steps in the initiation of $\mathrm{PHA}$ polymerization. Alternatively, $\mathrm{PhaC}_{\mathrm{Rs}}$ exists predominantly as a dimer; thus, dimerization does not appear to be the rate-limiting step. The specific activity against $3 \mathrm{HB}-\mathrm{CoA}$ never reached a plateau, even at high concentrations of $3 \mathrm{HB}-\mathrm{CoA}$ (Figure 3), suggesting that $\mathrm{PhaC}_{\mathrm{Rs}}$ has a low affinity for $3 \mathrm{HB}-\mathrm{CoA}$. The polymerization activity of $\mathrm{PhaC}_{\mathrm{Rs}}$ might follow a first-order reaction, which is proportional to the substrate concentration because of the predominance of its constitutively active dimeric form and its low substrate affinity.

$\mathrm{PhaC}_{\mathrm{Rs}}$ and $\mathrm{PhaC}$ from purple nonsulfur bacteria were classified as class I PhaCs (Figure 1). By contrast, PhaCs from A. vinosum and Synechocystis belong to class III. We verified that the whole genome sequences of $\mathrm{PhaC}$ from six purple sulfur bacteria strains (Thioflavicoccus mobilis, Thiocystis violascens, Marichromatium purpuratum, Thiorhodococcus drewsii, Thiocapsa marina, and Halorhodospira halophila) were available, and we determined that, similar to $A$. vinosum, five of the six strains have class III PhaCs, with $H$. halophila being the exception. In our previous study, certain differences in PHA production were found between purple nonsulfur bacteria and purple sulfur bacteria. Purple nonsulfur bacteria synthesized PHAs even when grown in the absence of nutrient deficiency, whereas purple sulfur bacteria synthesized PHAs only under nitrogenlimited conditions. We also demonstrated that purple nonsulfur bacteria synthesized $3 \mathrm{HB}$ and 3-hydroxyvalerate (3HV) copolymers, whereas purple sulfur bacteria produced $3 \mathrm{HB}$ homopolymers. Different PhaC properties between the purple nonsulfur bacteria and purple sulfur bacteria could result in differences in PHA production. Further analysis will be required to clarify these issues. The results of our study will contribute to a better understanding of PHA production.

\section{MATERIALS AND METHODS}

Cloning PhaC. $R$. sulfidophilum genomic DNA was isolated using a standard procedure. ${ }^{33} \mathrm{PhaC}$ was cloned using a twostep PCR method according to previous reports. ${ }^{34,35}$ The forward (FW) and reverse (RV) primer sequences for the first PCR reaction are listed in Table S1 of the Supporting Information. The first PCR program was identical to that of our previous report, ${ }^{34}$ and the second PCR reaction was conducted according to previous methods ${ }^{34,35}$ established for the N11 tag. The N11 tag is a modified version of the natural polyhistidine tag. ${ }^{35}$ A TEV protease recognition sequence was inserted to cleave the target $\mathrm{PhaC}$ from its partner protein in N11-tagged constructs. ${ }^{36}$ Table S2 of the Supporting Information lists the tags used in this study. After the 10th PCR cycle, the annealing temperature was changed to $64{ }^{\circ} \mathrm{C}$, and the duration of the extension was prolonged for $5 \mathrm{~s}$ per cycle. The last step was incubating the reaction mixture at 72 ${ }^{\circ} \mathrm{C}$ for $7 \mathrm{~min}$. The resultant product was immediately cooled to $10{ }^{\circ} \mathrm{C}$, and its concentration was determined using a PicoGreen dsDNA quantification kit (Invitrogen, Carlsbad, CA).

Cell-Free Synthesis of PhaC. The dialysis-mode cell-free protein synthesis method was used in this study, according to the methods presented in the literature. ${ }^{13,14,34,37}$ The internal solution $(36 \mathrm{~mL})$ was composed of the buffers, substrates, template DNA, and enzymes required for transcription and translation. The solution contained $55 \mathrm{mM}$ HEPES-KOH buffer ( $\mathrm{pH} 7.5$ ) containing $1.7 \mathrm{mM}$ dithiothreitol, $1.2 \mathrm{mM}$ adenosine-5'-triphosphate ( $\mathrm{pH} 7.0$ ), $0.8 \mathrm{mM}$ cytidine triphosphate $(\mathrm{pH} 7.0), 0.8 \mathrm{mM}$ guanosine- $5^{\prime}$-triphosphate $(\mathrm{pH} 7.0)$, $0.8 \mathrm{mM}$ uridine-5'-triphosphate $(\mathrm{pH} 7.0), 80 \mathrm{mM}$ creatine phosphate, $250 \mu \mathrm{g} / \mathrm{mL}$ creatine kinase, $4.0 \%$ polyethleneglycol (average molecular weight $8000 \mathrm{~g} / \mathrm{mL}$ ), $0.64 \mathrm{mM} \mathrm{3}, 5^{\prime}$-cyclic adenosine monophosphate, $68 \mu \mathrm{M} \mathrm{L}(-)$-5-formyl-5,6,7,8tetrahydrofolic acid, $0.05 \%$ sodium azide, $175 \mu \mathrm{g} / \mathrm{mL}$ Escherichia coli total transfer RNA (tRNA), $210 \mathrm{mM}$ potassium glutamate, $27.5 \mathrm{mM}$ ammonium acetate, $10.7 \mathrm{mM}$ magnesium acetate, $1.0 \mathrm{mM}$ each of the 20 amino acids, $6.7 \mu \mathrm{g} / \mathrm{mL}$ pK7CAT plasmid, $93 \mu \mathrm{g} / \mathrm{mL}$ T7 RNA polymerase, and $9.0 \mu \mathrm{L}$ of S30 extract. The S30 extract was prepared from the E. coli BL21 CodonPlus RIL strain (Stratagene, La Jolla, CA), as previously described. $^{34}$ Cell-free giant-scale dialysis using a dialysis membrane with a molecular-weight cutoff (MWCO) of 15 $\mathrm{kDa}$ (Spectra/Por 7, Pierce, Rockford, IL) was performed using previously reported reaction conditions. ${ }^{13}$ The internal solution 
was dialyzed in a dialysis tube (Spectra/Por 7, MWCO of 15 $\mathrm{kDa}$ ) against the external solution at $23{ }^{\circ} \mathrm{C}$ for $16 \mathrm{~h}$ while being shaken. $^{38}$

Purification of PhaC. To purify PhaC, $36 \mathrm{~mL}$ of the internal solution containing $\mathrm{PHA}_{\mathrm{Rs}}$ with the $\mathrm{N} 11$ tag with a TEV protease recognition sequence was purified using an ÄKTA Xpress FPLC (GE Healthcare, Little Chalfont, U.K.), according to protocols presented in the literature. ${ }^{13}$ The buffers used for the purification were described in our previous study. ${ }^{13}$ Briefly, the protein solution was purified using a HisTrap (5 mL, Ni-NTA column, GE Healthcare). To remove the tag, TEV was added to the eluted protein fraction at a final concentration of $10 \mu \mathrm{g} / \mathrm{mL}$. ${ }^{35}$ The protein in the flow-through fraction was loaded onto a HiLoad 16/60 Superdex 75 column (GE Healthcare) to concentrate the purified protein. The purified protein yield was determined using a Bio-Rad protein assay kit (Bio-Rad, Hercules, CA). Bovine serum albumin (BSA) was used as the protein standard. SDS-PAGE was performed using 15 to $20 \%$ precast Tris- $\mathrm{HCl}$ gels (DRC Co Ltd., Kyoto, Japan). The gels were stained with Coomassie brilliant blue.

Specific Activity Assay for PhaC. The specific activity of PhaC was determined by using the method of Gerngross et al., ${ }^{39}$ with modifications. ${ }^{13}$ Briefly, CoA released during the PhaC-catalyzed reactions can be measured using Ellman's reagent, 5,5'-dithiobis(2-nitrobenzoic acid) (DTNB). ${ }^{40}$ The assay mixture $(360 \mu \mathrm{L})$ contained $100 \mathrm{mM}$ sodium phosphate ( $\mathrm{pH} 7.5), 0.12 \mathrm{mM}$ Triton X-100, an appropriate amount of $3 \mathrm{HB}-\mathrm{CoA}(35,70,350,700,1000,1400$, or $2100 \mu \mathrm{M})$, and variable amounts of purified $\mathrm{PhaC}(0.75,7.5,10$, or $15 \mu \mathrm{M})$. The reactions were initiated by the addition of PhaC. DTNB was added to the mixture, and then, the absorbance was measured at $405 \mathrm{~nm}$. One unit was defined as the amount of enzyme required to catalyze the conversion of $1 \mu \mathrm{mol}$ of substrate/min. The specific activity was determined from the CoA release ranging from 0 to $1 \mathrm{~min}$ of the reaction because the reaction obviously lacked a lag phase.

Size Exclusion Chromatography and Native PAGE. The reaction mixture consisting of $\mathrm{PhaC}, 3 \mathrm{HB}-\mathrm{CoA}$, and 100 $\mathrm{mM}$ sodium phosphate $(\mathrm{pH} 7.5)$ in a total volume of $10 \mu \mathrm{L}$ was incubated for $15 \mathrm{~min}$ at $25{ }^{\circ} \mathrm{C}$. For TCEP treatment, the reaction mixtures were incubated for $60 \mathrm{~min}$ at $37{ }^{\circ} \mathrm{C}$ in the presence of $10 \mathrm{mM}$ TCEP. The reaction mixtures were then loaded onto a TSKgel G2000 SWXL column (TOSOH, Tokyo, Japan) equilibrated with $20 \mathrm{mM} \mathrm{NaPi}(\mathrm{pH} \mathrm{7.0)}$ containing 200 $\mathrm{mM} \mathrm{Na}_{2} \mathrm{SO}_{4}$ at $25{ }^{\circ} \mathrm{C}$. The reaction mixture containing $\mathrm{PhaC}$ was eluted with the same buffer at a flow rate of $1 \mathrm{~mL} / \mathrm{min}$ at $25{ }^{\circ} \mathrm{C}$. The molecular weight was determined from the calibration curve prepared using the following molecular weight standards: alcohol dehydrogenase $(150 \mathrm{kDa}, 7.7 \mathrm{~min})$, BSA (66 $\mathrm{kDa}, 8.4 \mathrm{~min})$, ovalbumin (44 kDa, $9.1 \mathrm{~min}), \mathrm{C} 2$ (16 kDa, 10.9 $\min )$, and aprotinin $(6.5 \mathrm{kDa}, 11.8 \mathrm{~min})$.

Native PAGE was carried out using precast gradient (412\%) Bis-Tris gels (Invitrogen, Carlsbad, CA), according to standard protocols. The gels were visualized by silver staining using a SilverXpress Silver Staining Kit (Invitrogen, Carlsbad, CA).

Phylogenetic Analysis. The phylogenetic tree was prepared based on the PhaC amino acid sequences of the 13 selected purple photosynthetic bacteria and constructed using Phylogeny (http://phylogeny.lirmm.fr/phylo_cgi/index. cgi). ${ }^{41-45}$ NJplot was used to display the phylogenetic tree. ${ }^{46}$
Quantitative RT-PCR Analysis. RNA of $R$. sulfidophilum was extracted under growth conditions. Total RNA was extracted from $R$. sulfidophilum cells using the RNAeasy Mini kit (QIAGEN, Tokyo, Japan). Using $1 \mu \mathrm{g}$ RNA as the template, cDNA was synthesized by the QuantiTect Reverse Transcription Kit (QIAGEN, Tokyo, Japan) following the manufacturer's protocol. The PCR was performed using a SsoAdvanced Universal SYBR Green Supermix (Bio-Rad, Hercules, USA), and the product was analyzed by StepOne (Thermo Fisher Scientific, Yokohama, Japan), according to the protocol. To determine the expression levels of the two phaC genes (WP_042463846 and WP 042457276), the following sets of primers were used: phaC (WP 042463846), phaC-F $\left(5^{\prime}\right.$-ATTGAGCCCGTCGATATCCT-3 $\left.{ }^{\prime}\right)$ and phaC-R (5'GCA GAC CCA TCC CTA TTT CA-3'); phaC (WP 042457276), phaC2-F (5'-CCG CCT GGA TCA TGA AAT AC- $\left.3^{\prime}\right)$, and phaC2-R (5'-ACA TGG CGA AGA CGG TAA AG-3'); rpoD, rpoD-F (5'-CTT GTC CTC GAT GAA ATC GC-3') and rpoD-R (5'-GTC CGC AAG GTG ATG AAG AT- $\left.3^{\prime}\right)$.

\section{ASSOCIATED CONTENT}

\section{Supporting Information}

The Supporting Information is available free of charge on the ACS Publications website at DOI: 10.1021/acsomega.7b00667.

Primer sequences of the tags and fragments, expression analysis of phac genes, SDS-PAGE analysis of $\mathrm{PhaC}_{\mathrm{R}}$, and size exclusion chromatography profiles of $\mathrm{PhaC}_{\mathrm{Rs}}$ in the presence of TCEP (PDF)

\section{AUTHOR INFORMATION}

\section{Corresponding Author}

*E-mail: keiji.numata@riken.jp. Phone: +81-48-467-9525. Fax: +81-48-462-4664 (K.N.).

ORCID $\odot$

Keiji Numata: 0000-0003-2199-7420

Notes

The authors declare no competing financial interest.

\section{ACKNOWLEDGMENTS}

This work was supported by the Grants-in-Aid for Scientific Research (M.H.-T.), the Impulsing Paradigm Change through the Disruptive Technologies Program (ImPACT) (K.N.), and the RIKEN Biomass Engineering Program (K.N.).

\section{REFERENCES}

(1) Numata, K.; Abe, H.; Iwata, T. Biodegradability of Poly(hydroxyalkanoate) Materials. Materials 2009, 2, 1104-1126.

(2) van Beilen, J. B.; Poirier, Y. Production of renewable polymers from crop plants. Plant J. 2008, 54, 684-701.

(3) Mooney, B. P. The second green revolution? Production of plantbased biodegradable plastics. Biochem. J. 2009, 418, 219-232.

(4) Snell, K. D.; Singh, V.; Brumbley, S. M. Production of novel biopolymers in plants: recent technological advances and future prospects. Curr. Opin. Biotechnol. 2015, 32, 68-75.

(5) Miyake, M.; Takase, K.; Narato, M.; Khatipov, E.; Schnackenberg, J.; Shirai, M.; Kurane, R.; Asada, Y. Polyhydroxybutyrate production from carbon dioxide by cyanobacteria. Appl. Biochem. Biotechnol. 2000, 84-86, 991-1002.

(6) Miyake, M.; Erata, M.; Asada, Y. A thermophilic cyanobacterium, Synechococcus sp. MA19, capable of accumulating poly- $\beta$-hydroxybutyrate. J. Ferment. Bioeng. 1996, 82, 512-514. 
(7) Liebergesell, M.; Hustede, E.; Timm, A.; Steinbüchel, A.; Fuller, R. C.; Lenz, R. W.; Schlegel, H. G. Formation of Poly(3Hydroxyalkanoates) by Phototrophic and Chemolithotrophic Bacteria. Arch. Microbiol. 1991, 155, 415-421.

(8) Higuchi-Takeuchi, M.; Morisaki, K.; Toyooka, K.; Numata, K. Synthesis of High-Molecular-Weight Polyhydroxyalkanoates by Marine Photosynthetic Purple Bacteria. PLoS One 2016, 11, No. e0160981.

(9) Rehm, B. H. A. Polyester synthases: natural catalysts for plastics. Biochem. J. 2003, 376, 15-33.

(10) Yuan, W.; Jia, Y.; Tian, J.; Snell, K. D.; Müh, U.; Sinskey, A. J.; Lambalot, R. H.; Walsh, C. T.; Stubbe, J. Class I and III polyhydroxyalkanoate synthases from Ralstonia eutropha and Allochromatium vinosum: characterization and substrate specificity studies. Arch. Biochem. Biophys. 2001, 394, 87-98.

(11) Lawrence, A. G.; Choi, J.; Rha, C.; Stubbe, J.; Sinskey, A. J. In vitro analysis of the chain termination reaction in the synthesis of poly(R)- $\beta$-hydroxybutyrate by the class III synthase from Allochromatium vinosum. Biomacromolecules 2005, 6, 2113-2119.

(12) Tian, J.; Sinskey, A. J.; Stubbe, J. Detection of intermediates from the polymerization reaction catalyzed by a D302A mutant of class III polyhydroxyalkanoate (PHA) synthase. Biochemistry 2005, 44, $1495-1503$.

(13) Numata, K.; Motoda, Y.; Watanabe, S.; Tochio, N.; Kigawa, T.; Doi, Y. Active Intermediates of Polyhydroxyalkanoate Synthase from Aeromonas caviae in Polymerization Reaction. Biomacromolecules 2012, $13,3450-3455$.

(14) Numata, K.; Motoda, Y.; Watanabe, S.; Osanai, T.; Kigawa, T. Co-expression of two polyhydroxyalkanoate synthase subunits from Synechocystis sp. PCC 6803 by cell-free synthesis and their specific activity for polymerization of 3-hydroxybutyryl-coenzyme A. Biochemistry 2015, 54, 1401-1407.

(15) Kim, J.; Kim, Y.-J.; Choi, S. Y.; Lee, S. Y.; Kim, K.-J. Crystal structure of Ralstonia eutropha polyhydroxyalkanoate synthase Cterminal domain and reaction mechanisms. Biotechnol. J. 2016, 12, 1600648 .

(16) Wittenborn, E. C.; Jost, M.; Wei, Y.; Stubbe, J.; Drennan, C. L. Structure of the Catalytic Domain of the Class I Polyhydroxybutyrate Synthase from Cupriavidus necator. J. Biol. Chem. 2016, 291, 2526425277.

(17) Chowdhury, W. Q.; Idehara, K.; Maeda, I.; Umeda, F.; Yagi, K.; Miura, Y.; Mizoguchi, T. Factors affecting polyhydroxybutyrate biosynthesis in the marine photosynthetic bacterium Rhodopseudomonas sp. strain W-1S. Appl. Biochem. Biotechnol. 1996, 57-58, 361-366.

(18) Masuda, S.; Hori, K.; Maruyama, F.; Ren, S.; Sugimoto, S.; Yamamoto, N.; Mori, H.; Yamada, T.; Sato, S.; Tabata, S.; Ohta, H.; Kurokawa, K. Whole-Genome Sequence of the Purple Photosynthetic Bacterium Rhodovulum sulfidophilum Strain W4. Genome Announc. 2013, 1, No. e00577-13.

(19) Solovyev, V.; Salamov, A. Automatic Annotation of Microbial Genomes and Metagenomic Sequences. In Metagenomics and its Applications in Agriculture, Biomedicine and Environmental Studies; Nova Science Publishers, 2011; pp 61-78.

(20) Numata, K.; Doi, Y. Biosynthesis of polyhydroxyalkanaotes by a novel facultatively anaerobic Vibrio sp. under marine conditions. Mar. Biotechnol. 2012, 14, 323-331.

(21) Numata, K.; Morisaki, K. Screening of Marine Bacteria To Synthesize Polyhydroxyalkanoate from Lignin: Contribution of Lignin Derivatives to Biosynthesis by Oceanimonas doudoroffii. ACS Sustainable Chem. Eng. 2015, 3, 569-573.

(22) Shimamura, E.; Kasuya, K.; Kobayashi, G.; Shiotani, T.; Shima, Y.; Doi, Y. Physical Properties and Biodegradability of Microbial Poly(3-Hydroxybutyrate-co-3-Hydroxyhexanoate). Macromolecules 1994, 27, 878-880.

(23) Brandl, H.; Knee, E. J., Jr.; Fuller, R. C.; Gross, R. A.; Lenz, R. W. Ability of the phototrophic bacterium Rhodospirillum rubrum to produce various poly (beta-hydroxyalkanoates): potential sources for biodegradable polyesters. Int. J. Biol. Macromol. 1989, 11, 49-55.
(24) Wodzinska, J.; Snell, K. D.; Rhomberg, A.; Sinskey, A. J.; Biemann, K.; Stubbe, J. Polyhydroxybutyrate synthase: Evidence for covalent catalysis. J. Am. Chem. Soc. 1996, 118, 6319-6320.

(25) Müh, U.; Sinskey, A. J.; Kirby, D. P.; Lane, W. S.; Stubbe, J. PHA synthase from Chromatium vinosum: cysteine 149 is involved in covalent catalysis. Biochemistry 1999, 38, 826-837.

(26) Li, P.; Chakraborty, S.; Stubbe, J. Detection of covalent and noncovalent intermediates in the polymerization reaction catalyzed by a C149S class III polyhydroxybutyrate synthase. Biochemistry 2009, 48, 9202-9211.

(27) Rietsch, A.; Beckwith, J. The genetics of disulfide bond metabolism. Annu. Rev. Genet. 1998, 32, 163-184.

(28) Schürmann, P.; Buchanan, B. B. The ferredoxin/thioredoxin system of oxygenic photosynthesis. Antioxid. Redox Signaling 2008, 10, $1235-1274$.

(29) Du, S.; Bird, T. H.; Bauer, C. E. DNA binding characteristics of RegA. A constitutively active anaerobic activator of photosynthesis gene expression in Rhodobacter capsulatus. J. Biol. Chem. 1998, 273, 18509-18513.

(30) Masuda, S.; Bauer, C. E. AppA is a blue light photoreceptor that antirepresses photosynthesis gene expression in Rhodobacter sphaeroides. Cell 2002, 110, 613-623.

(31) Bauer, C. E.; Elsen, S.; Bird, T. H. Mechanisms for redox control of gene expression. Annu. Rev. Microbiol. 1999, 53, 495-523.

(32) Stubbe, J.; Tian, J.; He, A.; Sinskey, A. J.; Lawrence, A. G.; Liu, P. Nontemplate-dependent polymerization processes: polyhydroxyalkanoate synthases as a paradigm. Annu. Rev. Biochem. 2005, 74, 433480.

(33) Maniatis, T.; Fritsch, E. F.; Sambrook, J. Molecular Cloning: A Laboratory Manual; Cold Spring Harbor Laboratory Press: Plainview, NY, 1982 .

(34) Kigawa, T.; Yabuki, T.; Matsuda, N.; Matsuda, T.; Nakajima, R.; Tanaka, A.; Yokoyama, S. Preparation of Escherichia coli cell extract for highly productive cell-free protein expression. J. Struct. Funct. Genomics 2004, 5, 63-68.

(35) Yabuki, T.; Motoda, Y.; Hanada, K.; Nunokawa, E.; Saito, M.; Seki, E.; Inoue, M.; Kigawa, T.; Yokoyama, S. A robust two-step PCR method of template DNA production for high-throughput cell-free protein synthesis. J. Struct. Funct. Genomics 2007, 8, 173-191.

(36) Dougherty, W. G.; Cary, S. M.; Parks, T. D. Molecular genetic analysis of a plant virus polyprotein cleavage site: a model. Virology 1989, 171, 356-364.

(37) Kigawa, T.; Yabuki, T.; Yoshida, Y.; Tsutsui, M.; Ito, Y.; Shibata, T.; Yokoyama, S. Cell-free production and stable-isotope labeling of milligram quantities of proteins. FEBS Lett. 1999, 442, 15-19.

(38) Spirin, A.; Baranov, V.; Ryabova, L.; Ovodov, S.; Alakhov, Y. A continuous cell-free translation system capable of producing polypeptides in high yield. Science 1988, 242, 1162-1164.

(39) Gerngross, T. U.; Snell, K. D.; Peoples, O. P.; Sinskey, A. J.; Csuhai, E.; Masamune, S.; Stubbe, J. Overexpression and purification of the soluble polyhydroxyalkanoate synthase from Alcaligenes eutrophus: evidence for a required posttranslational modification for catalytic activity. Biochemistry 1994, 33, 9311-9320.

(40) Ellman, G. L. Tissue sulfhydryl groups. Arch. Biochem. Biophys. 1959, 82, 70-77.

(41) Dereeper, A.; Guignon, V.; Blanc, G.; Audic, S.; Buffet, S.; Chevenet, F.; Dufayard, J.-F.; Guindon, S.; Lefort, V.; Lescot, M.; Claverie, J.-M.; Gascuel, O. Phylogeny.fr: robust phylogenetic analysis for the non-specialist. Nucleic Acids Res. 2008, 36, W465-W469.

(42) Edgar, R. C. MUSCLE: multiple sequence alignment with high accuracy and high throughput. Nucleic Acids Res. 2004, 32, 1792-1797.

(43) Castresana, J. Selection of conserved blocks from multiple alignments for their use in phylogenetic analysis. Mol. Biol. Evol. 2000, $17,540-552$.

(44) Guindon, S.; Dufayard, J.-F.; Lefort, V.; Anisimova, M.; Hordijk, W.; Gascuel, O. New algorithms and methods to estimate maximumlikelihood phylogenies: assessing the performance of PhyML 3.0. Syst Biol. 2010, 59, 307-321. 
(45) Anisimova, M.; Gascuel, O.; Sullivan, J. Approximate likelihoodratio test for branches: A fast, accurate, and powerful alternative. Syst Biol. 2006, 55, 539-552.

(46) Perrière, G.; Gouy, M. WWW-Query: An on-line retrieval system for biological sequence banks. Biochimie 1996, 78, 364-369. 